\title{
Abstract
}

Accounting is an important practical mechanism by which corporations are held to account for their performance and impact. This is consequential for corporate accountability for the conservation of natural capital. While there is clear evidence of increasing corporate accounting and reporting with respect to aspects of natural capital, however, such efforts are at best nascent. This is in part because the purpose and meaning of corporate natural capital accounting is not in itself well established, and in part because existing institutional structures and incentives do not lend themselves to giving a full account of natural capital impact. The paper argues that there is essentially a need for natural capital accounting and reporting systems that serve two distinct purposes. The first, which is the more likely to be satisfied by existing market structures, is oriented towards the informational needs of shareholders and is concerned with supporting a transition towards environmentally sustainable business models. The second, in contrast, acknowledges that a shareholderoriented perspective constrains natural capital to be important if, and only if, its conservation privately affects shareholders, which is unlikely to ensure an accounting that contributes to the conservation of natural capital as an end in itself. This second purpose of strengthening corporate natural capital accountability is unlikely to be satisfied within existing market structures; instead, it stands in need of a regulatory solution.

The paper is structured as follows. The next two sections of the paper consider the first of the questions above, by exploring an illustrative example of corporate natural capital accounting (Section 1) and by then, in Section 2, describing in high-level overview the environmental reporting currently undertaken by the corporate sector. Section 3 then explores the second of the two questions above, seeking to understand why companies account for (and report on) natural capital. Section 4 then offers a perspective on the limitations of corporate natural capital accounting in its current form, drawing implications for ways in which this accounting could be improved.

\section{Corporate natural capital accounting}


The term 'natural capital accounting' is starting find common usage, as evidenced for example in the contributions of a wide range of companies and other bodies to the work of the Natural Capital Coalition (NCC, 2016), or in the encouragement of the International Integrated Reporting Council for companies to report on the role that natural capital plays in creating business value (IIRC, 2013). Practice remains nascent, however, and there is no obvious answer to the question of what corporate natural capital accounting actually is. Published examples are few and far between. Some explicitly adopt a natural capital terminology, while others cover similar ground yet adopting a different language. The NCC's 'Natural Capital Protocol' is not, as might be expected, a 'how to' guide for natural capital accounting; instead it is an eclectic mix of different approaches, applied in different ways to varying ends, more a 'take your pick' document than an accounting standard (NCC, 2016).

All of this is to be expected. While conventional financial accounting is very well developed, and its meaning clear, the notion of natural capital has not yet reached the accounting mainstream. Moreover, there are not obvious ways in which the traditional purpose and design of financial accounting can be adapted or extended to embrace natural capital. Instead, we are in a period of experimentation and learning, a development stage that precedes any consensus on best practice.

One way to explore this space is to consider an illustrative example of natural capital accounting, both to give some focus to the discussion and also to provide a benchmark against which more general opportunities and challenges can be evaluated. Specifically, the approach taken in this section of the paper is to review the RSPB's natural capital account for its estate in England, which is based upon the Corporate Natural Capital Accounting (CNCA) framework of the Natural Capital Committee (NCC, 2015), and developed in partnership with the consulting firm eftec and the accounting firm PwC (eftec et al. 2015). The task that the RSPB sets itself is to develop 'a stock-based approach ... (which) enables values that relate to the stock (notably ethical considerations of preventing extinctions of other species and retaining the natural world for future generations) to be combined with other economic values.' In other words, the approach seeks to integrate economic decisionmaking with nature conservation, with the implicit assumption that financial calculation 
influence resource allocation decisions, and that the value of nature needs somehow to be 'translated' into a form that is recognised in that financial calculation.

In this endeavour, the RSPB is taking on three challenges. The first arises because nature is multi-faceted, providing value in different ways. This can be through the direct provision of goods and services, which might be transacted in markets or else might otherwise have economic benefits that are readily estimable. Yet it might also be relatively indirect, interrelated and elusive, as for example in the elements of an ecosystem that together provide for populations of pollinators, and so in turn enable crop fertilisation. The challenge here is to avoid being partial, measuring only that which is measurable, and by implication excluding from financial calculation that which is not measurable (RSPB, 2018, p12).

The second challenge is that there is a critical usage difference between natural assets and manufactured assets, and that the financial accounting system is designed for the latter and not the former. For the most part, manufactured assets wear out and are replaced. The accountant's depreciation charge is designed to capture this wearing out. If the revenue from usage of an asset exceeds the depreciation charge, then value has been created, and investing in a replacement asset is likely to be economically beneficial. In contrast, a distinctive feature of natural assets, which makes this income statement approach problematic, is that they often do not 'wear out' but instead renewably provide goods and services. Any decline in the state of the natural capital stock is therefore not simply a 'depreciation charge', in the sense of allocating the cost of consuming an asset over its useful life. It has instead a different meaning because, as described in the RSPB's report, 'there are likely to be critical levels of biodiversity below which ecological function is disrupted. If biodiversity declines beyond a certain point, the natural functioning of the system can change in the short or long term in unpredictable, non-linear, and non-marginal ways' (RSPB, 2018, p12). While manufactured capital can be fully depreciated and then replaced, the ecological function of natural capital can be lost irreversibly if 'depreciation' is allowed to continue below a critical, sustainable threshold. In short, while the notion of financial capital maintenance is similar to that of the maintenance of natural capital, there is also a critical sense in which it is fundamentally different. 
The third challenge is that the value of nature extends beyond goods and services, meaning that its importance risks being under-stated through the lens of goods and services alone. This is in two ways. First, there is a sort of latent value in nature, which can be characterised as having elements of optionality and of insurance. The optionality arises because nature may serve future functions that are as yet undiscovered. The insurance arises because nature is dynamic and adaptive, and so is 'by itself' able to alter the mix of goods and services that it provides. Second, and as described by the RSPB, there is the intangible, moral value that 'saving nature is the right thing to do as stewards of the planet'(RSPB, $2018, \mathrm{p} 12)$. The problem here, of course, is that nature has value, yet not in a form that lends itself to financial calculation.

The RSPB's approach to natural capital accounting comprises five steps. The first step, which is important but straightforward, is to 'define the organisation's commitments to the natural capital stock, including biodiversity.' This is simply so that the purpose of natural capital accounting is stated clearly, and thereby not 'lost' in the light of the practical difficulties of implementation. Step two is to create an asset register, which is an inventory of biophysical indicators of the extent, condition, and spatial configuration of natural capital assets. Step three is to estimate the maintenance and remediation costs to achieve the natural capital condition that is specified in the organisation's commitment. Step four is to identify, measure, and report the (physical) ecosystem service flows supported and delivered by the natural capital assets, and step five is then to value those service flows, including both the private value that they generate for the organisation and any external benefits derived by society. The sixth, and final, step then follows directly, which is to prepare a natural capital balance sheet, which presents the discounted present value of expected future net benefit flows provided by the natural capital assets, net of the (present value) of the maintenance costs from managing those assets. Following this process, the RSPB presents its natural capital balance sheet as follows (Table 1 ).

This balance sheet can be used to illustrate opportunities and challenges that arise for natural capital accounting, in itself and in its relationship to the established mainstream of financial accounting. 
An important challenge, for the development of accounting practice, is the question of scope. This is acknowledged clearly by the RSPB, as follows: 'the (CNCA) framework is designed to be used by landowners or other organisations which have responsibility for Natural Capital assets. Other approaches, such as the environmental profit and loss account developed by Kering, ${ }^{1}$ are more appropriate for those seeking to better understand their impacts through their supply chains.' At some level, the issue here is a very simple one, namely that assets and liabilities are not recognised in a set of accounts if they lie outside the direct ownership and control of the reporting entity (IASB, 2018). While, for example, natural capital is hugely important for the economic prosperity of companies such as Unilever or Nestlé, it is not something that they actually account for if asset ownership resides further up the supply chain. In other words, there is (or can be) an institutional disconnect between natural capital accounting and accountability for the economic activity that impacts upon that natural capital, and that also depends upon it. In this regard, the RSPB approach must be seen as limited in its generalisability.

There is also a second distinctive feature of the scope of accounting in the RSPB setting, which is that it has an explicitly social purpose. In general, accounting is a system for measuring economic position and performance, which enables a reporting entity to give an account, for the purpose of being held to account. In the case of the RSPB, it is being held to account for the conservation of nature, in effect for the benefit of society as a whole, for current and future generations. This is, of course, radically different from accountability in the corporate sector, in which the thing being accounted for is the financial position and performance of the reporting entity (i.e. the net assets that are owned and controlled by the entity, and changes therein), and where accountability is (primarily) to the providers of equity finance (see Framework in IASB, 2018). Accordingly, while the RSPB balance sheet explicitly takes into consideration externalities, corporate balance sheets do not. If a company has no current, legal obligation to 'make good' any depletion of natural capital caused by its activities, then it need not (indeed, should not) recognise any liability, nor write down the value of any asset. To the extent that the distinctive purpose of the RSPB's

\footnotetext{
${ }^{1}$ See Kering (2014).
} 
approach is largely captured in its treatment of externalities, there is obvious challenge in generalising this particular form of natural capital accounting.

A further issue arises from the method of measurement used by the RSPB. There is clear practical and conceptual merit in applying an economist's valuation approach in recognising both natural capital assets and corresponding liabilities, and yet there is also problematic discordance here with the approach traditionally used by accountants (CDSB, 2018). There is, in essence, a different emphasis placed by the economist and the accountant on the trade-off between relevance and reliability. To illustrate, the stock market capitalisation of a business is the most relevant metric for investment decision-making, yet the (very different) measure of equity in a company's accounts is more readily verifiable, and in that sense more reliable and less subjective. While the economist makes projections of future cash flows, with a view to informing prospective decisions, the accountant recognises the impossibility of giving an account of something that has not yet happened, and so the scope of accounting is historical; accounting asks how effectively an entity has performed, and what are the current economic rights and obligations of the entity, but not what the future might hold (Chambers, 1965; Barker and McGeachin, 2013; IASB, 2018). To this end, 'traditional' concepts such as stewardship, reliability, prudence and historical cost are all firmly established in accounting practice, the products of a long evolution (Watts, 2003; Basu and Waymire, 2006 and 2010). Accounting provides relatively reliable, credible (and auditable) information about the past as an input, to be used alongside other information, in making projections into the future; accounting is record keeping, not valuation.

As a result of this difference in approach to measurement, natural capital accounting cannot be integrated easily with financial accounting, which is problematic to the extent that the 'thing' being accounted for is given two very different, incommensurable representations. While the RSPB claims that the CNCA approach is designed to create an 'extended balance sheet,' it is really not doing this at all, but instead creating an alternative representation of both assets and liabilities. Assets are given a different measurement basis, liabilities are recognised by the economist when they would not be recognised by the accountant, and any distinction is lost between the reliably known and the unreliably estimated. There is no easy fix to this problem, and especially so because the accountant's approach is also sensitive to issues of agency, and of the incentives that the reporting entity (agent) may 
have to mislead the party to whom it is accountable (principal); Watts (2003). The accountant's approach, in the light of agency, is to disallow the subjective reporting of economic gains, and instead to (prudently) allow them to be deferred until such time as they become verifiable. The RSPB is instead doing the opposite, and while we can presume this to be fine in its specific setting as a nature conservation organisation, the same could not be presumed for a corporate entity seeking to overstate natural capital gains in order to enhance its commercial licence to operate.

A further difficulty, which is in practice unavoidable under either a valuation or an historical cost approach, and which the RSPB acknowledges, is that measurement is partial, and that only certain attributes of natural capital are in practice measurable. The expedient 'solution' here is that the asset remains unrecognised in the accounts, even when owned by the reporting entity and so in principle a reportable asset (a problem of measurability that natural capital shares with intangible assets; Lev and $\mathrm{Gu}, 2016)$. In this regard, there is only one aspect of natural capital that is explicitly addressed in financial accounting standards, namely the economic value of agricultural assets owned by the reporting entity (IAS 41 in IASB, 2018). The distinctive challenge with agricultural assets is that, in contrast with most assets where cost is more readily observable and verifiable than market value, the unit of account changes through natural processes, such as the growth of wood in a commercial forest or of fruit on a tree. The absence of a transaction-based unit of account lends itself to a presumption in accounting standards towards the use of a market value measure. In other respects, however, accounting practice remains undeveloped. An example is accounting for assets and liabilities arising from the EU carbon emissions trading scheme, with respect to which there is currently no accounting standard (Bebbington et al., 2008). There is also, in each of the points above, a more subtle observation to be made about the informational properties of accounting, and how these differ in an important way between financial accounting and natural capital accounting. This difference can perhaps best be characterised in terms of there being a greater emphasis on the income statement in the case of financial accounting (Penman 2009) and on the balance sheet in the case of natural capital accounting. The accountant's traditional 'matching' process, of associating the amounts that counterparties give up in exchange with one another, gives rise to a periodic measure of financial performance, of profit or loss, which can be viewed as the primary 
output of the financial accounting system (ljiri, 1975; Basu and Waymire, 2010). This works well, as a guide to prospective decision-making, as long as the past serves as a guide to the future. In the specific context of natural capital, however, an obvious limitation is that historical financial performance can be an unreliable indicator of future financial performance; for example, in a fishery that is harvested to depletion, the final catch is most likely profitable, yet that profit will be the last. The flaw here is that - except in cases where natural capital assets are owned by the reporting entity, and so where impairment losses are recognised - the financial accountant's income statement does not adequately take into consideration the sustainability of the supply of natural resources.

A final point is that the term 'accounting' can sometimes be used rather loosely, not least in the context of natural capital. The scope of accounting, as described above, is narrower than that of reporting. If, for example, a corporation reports on the state of its order book, or of its product development, then it is providing information that is a useful lead indicator of future revenue. As this revenue remains unearned at the reporting date, however, this information forms part of corporate reporting but is not (yet) included in the accounts; it can usefully be described as 'pre-financial' information (IASB, 2017). Similarly, the Financial Stability Board's Task Force on Climate-related Financial Disclosures (TCFD) calls for disclosure in annual financial reports (TCFD, 2016), yet its recommendations are concerned with reporting rather than with accounting, because they take the form of the estimated impacts of events that have not yet happened. Such data might, or might not, be commensurable with those reported in the financial statements. There is, for example, commensurability in the case of the above order book, and arguably so for carbon emissions (for which an offset price could be determined) or for the estimated financial effects of climate change, but increasingly less so for factors that can only subjectively be expected to affect firm value, for example through impact on reputation or through long-term and uncertain impact on supply chain sustainability. This is important because the 'answer' to the demand for natural capital accounting should not be understood through the lens of the financial statements alone; there is, instead, a broader space within which corporate reporting can be made effective. An important illustration of this is the problem that, while financial accounting does not take into consideration negative externalities, which are outside the scope of the financial statements, this does not imply that corporate reporting 
should take the same path. This is because, in one way or another, externalities might become internalised over time, making a current concern for society as a whole a prospective concern for shareholders, and so informationally relevant from a narrowly financial perspective.

\section{Corporate accounting and reporting in practice}

The RSPB example has been chosen above because - very unusually - it is a comprehensive, purposeful, carefully-considered and public illustration of natural capital accounting. In each of these respects, it differs considerably from general practice in corporate reporting. A simple difference is that explicit reference to 'natural capital' is less common than vague reference to concepts such as sustainability or environmental responsibility. More fundamentally, reporting practice varies widely, in purpose, scope, quality and transparency.

The most comprehensive global survey of corporate responsibility reporting found that around three quarters of the 4,900 companies studied issued some form of sustainability report (KPMG, 2017). The study provides evidence that these high levels of reporting can be found across all industry sectors, with no sector having fewer than $60 \%$ of its companies issuing reports. Moreover, the study found that, instead of the once commonplace practice of standalone sustainability reports being largely independent of mainstream corporate reporting, 'most of the world's biggest companies now integrate financial and non-financial data in their annual financial reports.' On the specific issue of carbon emissions and climate change, the study found that, in 2017 , as many as $67 \%$ of the world's largest companies (G250) disclosed targets to cut their carbon emissions (albeit that most of these firms did not relate their own targets to climate goals, such as the Paris Agreement's $2^{\circ} \mathrm{C}$ limit to global warming).

The current extent of corporate responsibility reporting, as summarised in the KPMG study, is remarkable by historical standards. One way to illustrate this is in Figure 1, which shows the number of multinational enterprises (MNEs) issuing a sustainability report. These data are taken from the Global Reporting Initiative (GRI) reporting database, and so eligibility for 
inclusion focuses on conformance with, or reference to, the GRI reporting framework (GRI, 2015). While there are a number of reporting frameworks being used in practice, GRI is perhaps the best known and most widely adopted; to illustrate, KPMG (2017) finds that GRI is the basis of sustainability reporting for $61 \%$ of companies in Europe.

The rate of growth in sustainability reporting is striking. There were fewer than $20 \mathrm{MNE}$ reporters in the year 2000 and fewer than 100 in 2004, yet more than 1000 by 2012 and almost 2000 by 2016 . On this evidence, the gap between corporate financial reporting and non-financial reporting appears to be closing remarkably rapidly, with the latter approaching the universal coverage that has long applied to the former.

Behind these headline 'compliance' rates there remain, however, important differences between financial reporting and sustainability reporting. The first is that the former is characterised by mandatory standards, issued by a single standard-setter, and the latter by voluntary frameworks and guidance, for which there are several credible sources. ${ }^{2}$ As KPMG (2017) notes, 'while initiatives to standardize reporting approaches will carry on and should be encouraged, it is likely that the international reporting landscape will continue to be fragmented and dynamic for the foreseeable future.' The second difference is that a high level of 'reporting' disguises a high level of variation in quality and scope. In the case of financial reporting, compliance implies standardisation: all companies report to the same informational requirements, audited to the same standards. There is no such equivalence in sustainability reporting, where there is relatively little agreed-upon reporting scope, measurement method and auditing standard. In contrast with financial accounting and reporting, there isn't a single approach that all companies can be said to use. Indeed, it is not obvious what 'corporate natural capital accounting' actually is. There are normative positions with respect to what it ought to be, and there is varied and emergent practice with respect to what form it appears to be taking, but there is not an underlying consensus.

What can be said is that, in principle, there is a distinction to be made between reporting either specifically to shareholders or, in some more general sense, to stakeholders (Freeman et al., 2010). While it might seem 'obvious' that sustainability reporting is aligned with the

\footnotetext{
2 The single financial reporting standard-setter globally (excluding the USA) is the International Accounting Standards Board (IASB), and in the USA it is the Financial Accounting Standards Board (FASB).
} 
latter of these two audiences, the evolution of practice has instead been away from the latter and towards the former (Milne and Gray, 2014; Deegan, 2017). In origin, the corporate sustainability (or 'CSR') report was positioned to treat financial accounting and sustainability accounting as essentially independent of one another, with there being conceptually different 'bottom lines' (the best known exposition of this approach is the 'triple bottom line' of Elkington (1997), which called for separate accountability for people, profit and planet). In this approach, the metrics used in a (standalone) environmental report need not be expressed in financial terms, and indeed typically are not so expressed. By design, there is therefore not necessarily commensurability with the financial statements, nor even among different metrics within the environmental report (Norman and MacDonald, 2004). Sometimes termed an 'inventory approach' (Gray, 1994; Lamberton, 2005), this method is most closely associated in practice with the Global Reporting Initiative (GRI, 2015). While this approach is increasingly 'unfashionable' (see below), it is by no means obsolete, and indeed its importance in practice is greater than the fashion admits. Moreover, such an approach should not be dismissed as being reporting rather than accounting. While explicitly incommensurable with financial accounting, these approaches exhibit attributes of an accounting system. The reporting of greenhouse gas emissions, for example, is historical, verifiable, commensurable and standardised (GHG; MacKenzie, 2009). There is, however, very little (if any) evidence in practice of an accounting system that combines financial and environmental accounting for a stakeholder audience, notwithstanding proposals in the research literature to that end (e.g. Rubenstein, 1992; Rambaud and Richard, 2015). Accounting practice is instead best described as comprising two different sets of accounts and reports, one financial and the other environmental, with the former unambiguously designed for shareholders, and the latter increasingly so.

In contrast with a stakeholder approach, there are several reporting frameworks that are explicitly designed for the informational benefit of shareholders. While these are relatively clear with respect to the reporting that would ideally take place, they are less clear on how such reporting can in practice be achieved. For example, the recommendations of the TCFD are that the estimated impacts of climate change adaptation should be disclosed in annual financial reports; yet those recommendations are not supported by any practical 
methodology (TCFD, 2017). Likewise, the International Integrated Reporting Council (IIRC) outlines a vision 'to align capital allocation and corporate behaviour to wider goals of financial stability and sustainable development through the cycle of integrated reporting and thinking,' yet it offers very little to underpin whether and how such integrated reports can be prepared in practice (IIRC, 2013).

A central challenge lies is in operationalising the notion of 'impact', a vague concept which is widely used in practice and yet rarely unpacked. Consider the following statement from KPMG (2017), which is typical.

Financial stakeholders - including investors, lenders and insurers - need to know what impacts your business is having on ... the environment, and how this could impact your business performance in the future. They want to see that you understand these impacts and to understand what your business response is. For example, is your company taking action that reduces risks, unlocks opportunities or builds capacity for future value creation?

The notion of impact in terms of business performance is central to the shareholder orientation, in effect calling for the integration of sustainability metrics into equity valuation. This is inherently challenging; how, for example, can an economic value be placed on a programme of sustainable supply chain certification? Much more straightforward is to report metrics that capture specific, local impacts - such as how many cubic meters of water a company has saved, or how many tonnes of carbon emissions it has reduced - notwithstanding that these cannot be aggregated into the valuation impact that is ultimately sought. And, anyway, the (economic) impact that is sought is derivative, because it is presumed by KPMG (and others) to be a consequence of the (physical) impact of business activity on the environment. Note that the concern is not with corporate impact on the environment per se, but instead only with that impact in so far as it causes an impact on shareholder value; externalities can safely be ignored. But then note the confusion in this positioning. A company that is exposed to the effects of climate change need not itself have caused those effects. The shareholder is ultimately concerned with a company's dependency on natural resources, whether or not the impact of the company itself was responsible for threatening the sustainability of those resources. And even if a company 
does report on its dependencies - including those beyond its direct control, and so beyond its responsibility - then this is ultimately only reactive rather than proactive. Consider, for example, a tea business that reports climate-related risk to the sustainability of the plantations in its supply chain. The job of sustainability reporting is 'done' from a shareholder perspective if the stock price is efficiently adjusted downwards in anticipation of the risks to the business; it matters not that, from a social perspective, there may no longer be any tea to drink. More effective, from a natural capital perspective, would be to link corporate reporting on environmental impact to science-based social targets, aligned for example with the UN's Sustainable Development Goals (SDGs). And yet this would imply a stakeholder orientation, which runs against the direction of travel of corporate reporting frameworks and practice.

A further challenge concerns the approach to monetisation, which can vary according to the notion of capital being employed and the associated method of measurement (Gray, 2010). One approach is to conceptualise natural capital in financial terms, as an economic valuation of natural resources. Measurement under this approach might be based upon observed market prices, or alternatively upon some alternative method of approximating such prices, for example through hedonistic pricing or survey-based measures of willingness to pay. Impact on natural capital can be measured here in terms of economic consequences for third parties, such as damages incurred or opportunities foreclosed (Antheaume, 2004; Bebbington et al., 2007). But this tends towards valuation, rather than accounting, because it is grounded in the speculative valuation of future economic benefits. Alternatively, ntural capital accounting can be grounded in the observable state of nature at the present time, and so in an accountability through a relatively reliable system of measurement (Barton, 1999). Such an approach would be concerned directly with the physical maintenance of the natural resources themselves (Gray,1992 and 1994; Bebbington and Gray, 2001; Milne and Gray, 2013; Helm, 2015; Barker and Mayer, 2017).

The overall message here is that, in sharp contrast with corporate financial accounting, corporate natural capital accounting has elements of ambiguity, rhetoric, unacknowledged complexity, variation and confusion. While, in many ways, it has made serious and impressive progress in recent years, it remains a nascent practice. 


\section{Why do corporations undertake natural capital accounting and reporting?}

Taken together, the discussion in Sections 1 and 2 suggests that natural capital accounting is under-developed, while also conceptually and practically challenging. Moreover, it is at odds in certain important ways with the institutional purpose and structure of corporations and, therefore, at odds also with the incentives that lie behind corporate reporting. And yet the evidence also suggests a dramatic increase in corporate reporting, suggesting some form of powerful motivation to do at least something. In this section of the paper, that motivation is explored further. If some light can be shed on why companies do what they do, and in what ways they are not incentivised to do what they might do, then some foundation is laid for the discussion in Section 4, which reviews possible policy implications for enhancing natural capital accounting and reporting.

In very brief outline, the argument presented below is that the reporting behaviour of corporations can be understood as driven by three (related) forces - legal, economic and conventional; each of these is described in turn in this section.

Legal

The most obvious motivation for corporate natural capital reporting is that of legislative requirement (see Table 2). In the UK, Section 172 of the Companies Act 2006 imposes on a director the duty to 'act in a way he considers, in good faith, would be most likely to promote the success of the company for the benefit of its members as a whole' and, in so doing, to have regard to social, environmental and governance factors. This duty is expressed as a reporting obligation in Section 414C, which sets out the required contents of a strategic report, the purpose of which is 'to inform members of the company and help them assess how the directors have performed their duty under section 172 ... The strategic report must contain a review of the company's business, including its principal risks and uncertainties, its development and performance during the financial year and position at the end of that year. This must include analysis using financial key performance indicators relating to environmental matters, if such is necessary for a 'proper understanding.' 
UK legislation was amended in 2016 to incorporate the requirements of the EU NonFinancial Reporting Directive (EU, 2014). In Section 6, the Directive calls for 'a non-financial statement containing information relating to at least environmental matters ... (to) include a description of the policies, outcomes and risks related to those matters and should be included in the management report of the undertaking concerned.' With respect to environmental matters, Section 7 of the Directive calls for 'details of the current and foreseeable impacts of the undertaking's operations on the environment, and, as appropriate ... the use of renewable and/or non-renewable energy, greenhouse gas emissions, water use and air pollution,' while Section 8 calls for 'adequate information' concerning 'principal risks of severe impacts, along with those that have already materialised ... (which) may stem from the undertaking's own activities or may be linked to its operations, and, where relevant and proportionate, its products, services and business relationships, including its supply and subcontracting chains.'

UK adoption of the EU Non-Financial Reporting Directive took the form of the Companies, Partnerships and Groups (Accounts and Non-Financial Reporting) Regulations 2016, which inserted two new sections (414CA and 414CB) into the Companies Act 2006. Section 414CA sets out the requirement for (mostly large) companies to include a non-financial information statement in their strategic report. Section $414 C B$ provides that this statement must contain information to the extent necessary for an understanding of the company's development, performance and position and the impact of its environmental activity (along with specified other 'non-financial matters'). The information must include a brief description of the company's business model, a description of the policies pursued by the company in relation to such non-financial matters, the outcome of these policies, a description of the principal risks relating to such non-financial matters and how the company manages such risks. There is a 'comply or explain' approach: if a company does not pursue policies in relation to one or more of the non-financial matters, it must give a clear and reasoned explanation for not doing so.

Finally, the Companies Act 2006 also requires specific disclosures concerning greenhouse gas emissions, including (for the current and prior year) the annual quantity of emissions in tonnes of carbon dioxide equivalent, both from activities for which the company is responsible and from the purchase of electricity, heat, steam or cooling by the company for 
its own use, and to include at least one ratio which expresses the company's annual emissions in relation to a quantifiable factor associated with the company's activities.

While all of these legal requirements appear comprehensive, there are two important limitations, which are highlighted by the distinctive nature of the specific disclosures concerning greenhouse gas emissions, in comparison with the more general disclosures concerning environmental impact. First, the disclosure requirements for greenhouse gas emissions are not just specific but also mandatory. In contrast, the more general disclosures are essentially left to the discretion of management. This is highlighted in guidance issued by the London Stock Exchange (LSE), which sets out recommendations for good practice in environmental, social and governance (ESG) reporting (LSE, 2017). A striking feature of this guidance - which is in sharp contrast with financial reporting - is that it is non-specific, as follows, with respect to authoritative standards, frameworks or metrics for the reporting of environmental impact.

While we are some way from a global consensus on reporting standards, the frameworks developed by the following organisations (in no specified order) are the ones most widely cited by investors: the Global Reporting Initiative (GRI), the International Integrated Reporting Council (IIRC), the Sustainability Accounting Standards Board (SASB), the UN Global Compact, the CDP (formerly the Carbon Disclosure Project), the Climate Disclosure Standards Board, and the FSB Task Force on Climate-Related Financial Disclosures.

This vagueness is not limited to the UK. Across Europe, companies subject to the EU NonFinancial Reporting Directive (EU, 2014, Section 9) 'may rely on national frameworks ... (or) the Global Reporting Initiative, or other recognised international frameworks;' there are no specific requirements. Indeed, even the selection of one framework over another does not resolve the issue, because each, in various ways, continues to allow significant room for management judgement about what to report on, and in what way.

The second important difference between the specific and the general disclosures required by the Companies Act 2006 concerns the purpose for which the disclosure is made. There is, in essence, stakeholder reporting motivating the specific disclosure, and shareholder 
reporting motivating the general disclosure. Recall that the duty of directors under $\$ 172$ is to shareholders. This duty dominates and guides the duty to report. It follows that directors are not obliged to report the environmental impact of corporate activity, as the legislation might appear to suggest, but instead to report that impact only in so far as it is relevant in promoting the success of the company for the benefit of its members. In contrast, the specific disclosures concerning greenhouse gas emissions are required whether or not they are material to shareholders, and in that sense are designed with a public interest that is not aligned with the s172 duty.

\section{Economic}

Corporate reporting can also be motivated by economic self-interest, with respect to both product markets and capital markets. This is most commonly understood in the research literature through the lens of legitimacy theory (Deegan, 2014). The essential idea is that organisations are enabled to exist because the society in which they operate views them as legitimate (Suchman, 1995). If there is any threat to that legitimacy, then there is an economic interest in responding to that threat. One might think of a 'licence to operate' being in substance an intangible asset of an organisation, with investments in corporate reporting being made to either grow or restore that asset (Dowling and Pfeffer, 1975). Similarly, although from a somewhat different perspective, one might theorise corporate reporting in terms of maintaining economically beneficial relationships with different categories of stakeholder (Deegan and Blomquist, 2006).

An implication of legitimacy theory is that, for a range of reasons, the extent of corporate reporting will vary across different corporations, and also across different industries (Patten, 1992). There might, for example, be high levels of reporting if a given business model is explicitly positioned in the realm of environmental responsibility, where the potential impairment loss from a legitimacy crisis is relatively large, and so where there is greater reward from maintaining reputation. Somewhat paradoxically, given the assumption of economic self-interest, there might also be greater corporate reporting in sectors where environmental impact is greatest, and so where there is in principle more 'bad news' to be reported. Or there might instead be low reporting in either of these cases. The first of these two corporations might perceive that being too transparent might either expose it to 
challenge or represent itself as 'protesting too much'. The second, meanwhile, might prefer a 'nothing to see here' approach, or else it might simply perceive that its legitimacy gap cannot be closed and is not worth investing in.

There are two common threads in these examples. The first is the enactment of a cost benefit analysis, whereby the corporation is weighing up the economic impact of corporate reporting, given its perception of the scale and nature of any threat or opportunity to its legitimacy. This is a positive theoretical lens, seeking to explain practice without making any normative assumptions about what that practice ought to be. An implication is that high levels of corporate reporting could be consistent with anything from genuinely responsible business practice to 'greenwashing', where the latter involves only the (false) representation of responsibility in the pragmatic service of economic self-interest (Deegan et al., 2002). The second common thread is that the optimal level of corporate reporting will vary over time as any given corporate activity is perceived to be more or less legitimate (Brown and Deegan, 1998; Islam and Deegan, 2010). The theory would predict, for example, that an increasing salience of plastic waste as a social issue would lead to greater corporate reporting in that regard; it is not that plastic waste has objectively become an issue of environmental damage but instead that it has subjectively become so in social perception, and has thereby become important for corporate legitimacy (Suchman, 1995). There is, of course, a self-fulfilling, constitutive role for corporate reporting in this regard, because the act of reporting might in itself lead to creating an issue of social concern. (And there might also be the opposite outcome, whereby the effect of 'greenwashing' is to divert social perception from the recognition of an environmental concern; Deegan et al., 2002.)

\section{Conventional}

The third explanation for corporate reporting has overlaps with legal and economic perspectives, yet it is also distinctive in important ways. The lens here is institutional theory, a sociological perspective that sets calculative self-interest in a broader context of social norms, which are shaped by a variety of institutional pressures (Di Maggio and Powell, 1983; Scott, 1995; Higgins and Larrinaga, 2014). According to this perspective, the regulatory and coercive forces of the law, reporting standards and markets act as a partial explanation of corporate behaviour. In addition, institutional rules, norms and beliefs 
develop within distinct organisational fields (Hoffman, 1999). These are learned through peer group socialisation, and they become taken for granted and reproduced, thereby forming socially constructed behavioural constraints (Berger and Luckman, 1967). If, for example, an organisation signs up to a reporting framework (such as GRI or TCFD) because it becomes perceived as 'the right thing to do', then this can explained in terms of 'fitting in' with a social expectation, as opposed to there being any more fundamental alignment with the underlying purpose of the framework; it would simply be 'unthinkable' to do otherwise (Oliver, 1991). Such a motivation might help to explain why there is variation in reporting among different cultural settings, and not just across industries (Cho, Chen and Roberts, 2008; Kolk, 2010). For example, Bebbington et al. (2009) found, in a sample of New Zealand firms, that the decision to (voluntarily) adopt environmental reporting was symbolic of a commitment to sustainability, rather than a calculated economic move. This institutional perspective is in some sense anticipated by Friedman (1970), who argued that the responsibility of business is to 'make as much money as possible while conforming to the basic rules of the society, both those embodied in law and those embodied in ethical custom' (italics added).

An institutional perspective offers a distinctive explanation of change. For example, the effect of a corporate environmental crisis, such as Exxon Valdez, can be to upset the stability of a social norm, so re-writing the institutional rules (Hoffman, 1999). The rule-writer itself adopts a particular significance in this context. For example, an organisation such as the World Business Council for Sustainable Development (WBCSD) is global, and thereby likely to define the organisational field at that level, yet it is also a corporate coalition, and therefore likely to be shaped and influenced by taken-for-granted norms and values within the corporate sector. In general, while there is a stability to any accepted convention, there is also vulnerability to disruption (as, for example, in Keynes' (1936) analysis of investment behaviour). In this sense, the forces of convention can be understood as dynamic, with implications for how corporate behaviour changes over time. Not least, conventions shape, and are shaped by, the inherent uncertainty of business decisions, and the associated subjectivity in determining the 'right' course of action, which provides both the flexibility and the security in social conformance. 


\section{Implications for corporate natural capital accounting and reporting}

Several themes run throughout this paper. One of these concerns the audience to whom accountability is held, in particular the distinction between shareholders and some broader stakeholder/social audience. A second theme concerns the distinction between accounting and reporting, and the extent to which each operates under different constraints and serves different purposes. A third theme concerns the difference in scope between financial accounting and natural capital (more generally, sustainability) accounting, and the limited overlap between these two domains. The significant recent growth in sustainability reporting has, for the most part, converged on specific responses to each of these three themes. The effect is a work-in-progress that is increasingly addressing sustainability in a particular, and partial, way. The primary audience is the shareholder rather than society, the primary vehicle is reporting rather than accounting, and a solution to the challenge of overlap is at best in its early stages of development. These points can be summarised by comparing sustainability accounting and reporting against the benchmark of mainstream financial accounting and reporting.

On the first point, the audience for financial accountability is unambiguously the shareholder. In contrast, there is a bigger picture of responsibility in the domain of natural capital, because corporate impact on the natural world is consequential for society at large, including those as yet unborn or otherwise without a voice in market transactions. The picture drawn in this paper, however, is one of shareholder primacy in sustainability reporting. The difference is one of priority. If a company operates to the highest environmental standards that it can 'afford', subject to the constraint of maximising shareholder value, but in operating under this constraint it contributes to the unsustainable depletion of natural capital, then the shareholder is afforded priority over society at large. There might, in practice, be significant overlap between the two perspectives, as for example if a corporation directly depletes its own supply chain, or of its adverse environmental impacts make it vulnerable to potential taxation, adverse consumer reaction or some other economic internalisation. Yet there remains a fundamental difference in principle between these two perspectives. A shareholder perspective has an instrumental focus on accounting for natural capital dependencies, which are factors affecting the capacity of the business to sustain value creation for shareholders. A stakeholder 
perspective, on the other hand, would focus on impacts, which are the consequences of corporate activity for the sustainability of natural capital. Moreover, existing legal, economic and conventional forces can all be described as lined up on the shareholder's side of this distinction: corporate law prioritises the shareholder, the economic evaluation of the licence to operate is through a shareholder value lens, and social convention is rooted in the norms of the market economy and of shareholder capitalism. It is not surprising that - to name a few examples - the TCFD, Integrated Reporting, SASB, CDP and the Strategic Report are all aligned with shareholder value creation, and also that they allow management considerable flexibility in (voluntarily) determining the scope and content of their environmental reporting. The obvious concern here, from a stakeholder perspective, is that the term 'sustainability' comes to mean little more than sustainable financial profit, making it a 'rhetorical diversion' (Milne and Gray, 2013, p14) that gives false reassurance about business-as-usual (Norman and MacDonald, 2004; Deegan, 2013; Cho, et al., 2015; Schneider, 2015).

The second observation is that while the financial domain is firmly anchored in the accounts, with broader reporting playing a secondary role, the sustainability domain is in some sense structured the other way around. At the heart of the financial are mandatory standards relating to historical performance and current position and, while there is a degree of management judgement on issues such as materiality and presentation, there are clear, comprehensive rules to be followed, which prioritise relevance, reliability, completeness and comparability (IASB, 2018), and adherence to which is audited. In common with sustainability reporting, there are also requirements in the strategic report to provide an expanded discussion, yet these requirements allow considerable judgement, making them in effect voluntary; within broad guidelines, management can report as it thinks best. Against this benchmark, sustainability reporting is mostly lacking in the formal structure of accounting. With the exception of statutory carbon emissions reporting, areas that could in principle be subject to mandatory accounting standards are instead maintained in the reporting sphere, with a corresponding lack of requisite consistency, rigour and reliability. What is striking here is the absence in the sustainability domain of the type of accounting standards that dominate, and are taken as given, in the financial domain. To illustrate, it would be unthinkable for companies to be allowed to report financial performance in 
whatever way they felt best, and yet such is the current state of play with sustainability performance.

The third, and final, observation is that there is limited effective overlap between financial accounting and natural capital accounting. This is primarily a matter of scope, because the financial accounts hold management accountable for the private property rights (and obligations) that are controlled by the company, and not for natural capital that is held in its supply chain, or downstream of its activities, whether that capital is privately owned or held in common by society (CDSB, 2018). If the conservation of natural capital is an end in itself, it follows that some form of distinctive consideration of natural capital accounting is required beyond the current constraints of financial accounting.

Each of these themes points to an omission in the current reporting environment, namely a standard-setting body for natural capital accounting. Such a body would serve the public interest, acting as a balance to extant forces that serve the interests of shareholders. It would be explicitly concerned with accounting, rather than reporting. In other words, it would concern itself with giving an account, with the accountability of the corporate sector for historical performance, and to that end it would be anchored in reliable measurement, consistently and comprehensively applied and audited. In turn, and just as is the case for financial accounting, it would provide a foundation for corporate reporting, which would take the form of more subjective, prospective and descriptive material, designed to complement the accounts and provide a guide to how management is running the business. By way of illustration, the natural capital accounts would include data on carbon emissions, the financial accounts would include data on carbon taxes (if any) and on energy costs, and the strategic report would explore issues such as the company's climate adaptation strategy and the risks and opportunities it faces in relation to climate change. There would be both market-based and regulatory approaches in effect, working together. The former would continue to underpin the already successful rate of growth and development of the sustainability report, aligning it with the strategic report, while the latter would provide the mandatory, comprehensive and comparable accounting foundations that are essential for an effective accountability, for both financial performance and natural capital impact. 


\section{References}

ACCA (2016). Mapping the sustainability reporting landscape: Lost in the right direction. London: Association of Chartered Certified Accountants.

Antheaume, N. (2004). Valuing external costs - from theory to practice: implications for full environmental cost accounting. European Accounting Review, 13(3): 443-464.

Barker, R. and McGeachin, A. (2013). 'Why is there conceptual inconsistency in accounting for liabilities in IFRS?' Accounting and Business Research, 43(6): 579-604.

Barker, R. and Penman, S. (2018). Moving the Conceptual Framework Forward: Accounting for Uncertainty. Contemporary Accounting Research (forthcoming).

Barker, R. and Mayer, C. (2017). How Should a 'Sustainable Corporation' Account for Natural Capital? Saïd Business School Working Paper 2017-15.

Barton, A. (1999). 'A trusteeship theory of accounting for natural capital assets.' Abacus, 35(2): 207-222.

Basu, S., and G. B. Waymire. 2006. Recordkeeping and human evolution. Accounting Horizons 20 (3): 201-229.

Basu, S., and G. B. Waymire. 2010. Sprouse's what-you-may-call-its: Fundamental insight or monumental mistake? Accounting Historians Journal 37 (1): 121-148.

Bebbington, J. and Larrinaga-Gonzalez, C. (2008), 'Carbon trading: accounting and reporting issues', European Accounting Review, Vol. 17 No. 4, pp. 697-717.

Bebbington, J., Higgins, C. and Frame, B. (2009). Initiating sustainable development reporting: evidence from New Zealand, Accounting, Auditing \& Accountability Journal, 22(4): 588-625.

Bebbington, J., \& Gray, R. (2001). An account of sustainability: failure, success and a reconceptualization. Critical Perspectives on Accounting, 12, 557-587.

Bebbington, J., Brown, J. \& Frame, R. (2007). Accounting technologies and sustainability assessment models. Ecological Economics, 61: 224-236.

Berger, P. and Luckman, T. (1967). The Social Construction of Reality: A Treatise in the Sociology of Knowledge. Harmondsworth: Penguin Books.

Brown, N. and Deegan, C. (1998). The public disclosure of environmental performance information-a dual test of media agenda setting theory and legitimacy theory. Accounting and Business Research, 29:1, 21-41

CDSB (2018). Uncharted waters: how can companies use financial accounting standards to deliver on the TCFD recommendations? London: Climate Disclosure Standards Board.

Chambers, R., 1965. Measurement in accounting. Journal of Accounting Research (Spring), 32-62.

Deegan, C. (2017). Twenty five years of social and environmental accounting research within Critical Perspectives on Accounting: Hits, misses and ways forward. Critical Perspectives on Accounting, 43, 65-87. 
Deegan, C. and Blomquist, C. (2006), 'Stakeholder influence on corporate reporting: an exploration of the interaction between WWF-Australia and the Australian minerals industry', Accounting, Organizations and Society, Vol. 31 Nos 4-5, pp. 343-72.

Deegan, C., Rankin, M. and Tobin, J. (2002), An examination of the corporate social and environmental disclosures of BHP from 1983-1997: A test of legitimacy theory, Accounting, Auditing \& Accountability Journal, 15(3): 312-343.

Deegan, C. (2014), An overview of legitimacy theory as applied within the social and environmental accounting literature, in Bebbington, J., O'Dwyer, B. and Unerman, J (Eds), Sustainability Accounting and Accountability, Routledge, London.

Deegan, C. (2013). The accountant will have a central role in saving the planet . . really? A reflection on green accounting and green eyeshades twenty years later. Critical Perspectives on Accounting, 24, 448-458.

DiMaggio, P., \& Powell, W. (1983). The Iron Cage Revisited: Institutional Isomorphism and Collective Rationality in Organizational Fields. American Sociological Review, 48(2), 147-160.

Dowling, J. and Pfeffer, J. (1975), 'Organization legitimacy: social values and organizational behaviour', Pacific Sociological Review, Vol. 28 No. 1, pp. 122-36.

EU (2014). Directive 2014/95/EU of the European Parliament and of the Council. Brussels: European Union.

eftec, RSPB and PwC (2015) Developing Corporate Natural Capital Accounts, Final Report for the Natural Capital Committee.

Elkington, J. (1997). Cannibals with forks: The Triple Bottom Line of 21st century business. Oxford: Capstone Publishing.

Freeman, R.E., J. Harrison, A. Wicks, B. Parmar, and S. de Colle (2010). Stakeholder Theory: The State of the Art. Cambridge: Cambridge University Press.

Friedman, M. (1970) 'The social responsibility of business is to increase its profits', The New York Times Magazine, 13 September.

GRI (2015). Global Sustainability Reporting Guidelines. Amsterdam: GRI.

Gray, R. (1992). Accounting and environmentalism: An exploration of the challenge of gently accounting for accountability, transparency and sustainability. Accounting Organizations and Society, 17, 399-425.

Gray, R. (1994). Corporate reporting for sustainable development: Accounting for sustainability in 2000AD. Environmental Values, 3, 17-45.

Gray, R. (2010). Is accounting for sustainability actually accounting for sustainability. . .and how would we know? An exploration of narratives of organisations and the planet. Accounting Organizations and Society, 35, 47-62.

Helm, D. (2015). Natural Capital. New Haven, CT: Yale University Press.

Higgins, C. and Larrinaga, C. (2014), 'Sustainability reporting: insights from neo-institutional theory', in Bebbington, J., O'Dwyer, B. and Unerman, J (Eds), Sustainability Accounting and Accountability, Routledge, London. 
Hoffman, A. (1999). Institutional Evolution and Change: Environmentalism and the U.S. Chemical Industry. Academy of Management Journal, 42(4): 351-371.

IASB (2018). International Financial Reporting Standards. London: IASB.

IIRC (2013). The international framework. Integrated Reporting Committee. London: IIRC.

ljiri, Y. 1975. Theory of accounting measurement. Sarasota, FL: American Accounting Association.

Islam, M. and Deegan, C. (2011). Media pressures and corporate disclosure of social responsibility performance information: A study of two global clothing and sports retail companies, Accounting and Business Research, 40(2): 131-148.

KPMG (2017). Survey of Corporate Responsibility Reporting. Amsterdam: KPMG.

Kering (2014). Kering Environmental Profit \& Loss: Methodology and 2013 Group Results.

Keynes, J.M. (1936). The General Theory of Employment, Interest and Money. London: Macmillan.

Kitzmueller, M, \& Shimshack, J., 2012 Economic Perspectives on Corporate Social Responsibility, Journal of Economic Literature, 50(1): 51-84.

Kolk, A. (2010). Trajectories of Sustainability Reporting by MNCs. Journal of World Business. 45. 367-374.

Lamberton, G. (2005). Sustainability accounting - A brief history and conceptual framework. Account Forum, 29, 7-26.

Lev, B. and Gu, F. (2016). The End of Accounting. Hoboken, New Jersey: Wiley.

LSE (2017). Revealing the full picture: your guide to ESG reporting. London: London Stock Exchange.

MacKenzie, D. (2009). Making things the same: Gases, Emission Rights and the Politics of Carbon Markets. Accounting, Organizations and Society, 34(3-4), 440-455.

Miller, P. and M. Power (2013). Accounting, organizing and economizing: connecting accounting research and organization theory. The Academy of Management Annals, 7(1), 557-605.

Milne, M. J., \& Gray, R. (2013). W(h)ither ecology? The TBL, the GRI, and the institutionalisation of corporate sustainability reporting. Journal of Business Ethics, 118,13-29.

Milne, M. and Gray, R (2014), 'Future prospects for corporate sustainability reporting', in Bebbington, J., O'Dwyer, B. and Unerman, J (Eds), Sustainability Accounting and Accountability, Routledge, London.

NCC (2015). Corporate Natural Capital Accounting. London: Natural Capital Committee.

NCC (2016). Natural Capital Protocol. London: Natural Capital Coalition.

Neumayer, (2013). Weak vs Strong Sustainability: Exploring the Limits of Two Opposing Paradigms (4th edition). Cheltenham, UK: Edward Elgar. 
Nissim, D., and S. H. Penman. 2008. Principles for the application of fair value accounting. White Paper No. 2, Center for Excellence in Accounting and Security Analysis, Columbia Business School.

Nobes, C. (2015). Accounting for capital: the evolution of an idea. Accounting and Business Research, 45(4): 413-441.

Norman, W., \& MacDonald, C. (2004). Getting to the bottom of Triple Bottom Line. Business Ethics Quarterly, 14, 243-262.

Oliver, C. (1991). Strategic Responses to Institutional Processes. Academy of Management Review, 16(1), 145-179.

Patten, D.M. (1992), 'Intra-industry environmental disclosures in response to the Alaskan oil spill: a note on legitimacy theory', Accounting, Organizations and Society, Vol. 17 No. 5, pp. 471-5.

Penman, S. H. 2009. Accounting for intangible assets: There is also an income statement. Abacus 45 (3): 359-371.

RSPB (2018). Accounting for Nature: a natural capital account of the RSPB's estate in England.

Rambaud, A. and J. Richard (2015). 'The "Triple Depreciation Line" instead of the "Triple Bottom Line": Towards a genuine integrated reporting.' Critical Perspectives on Accounting, 33: 92-116.

Rubenstein, D. B. (1992). Bridging the gap between green accounting and black ink. Accounting Organizations and Society, 17, 501-508.

Scott, W. (1995). Institutions and organizations. Thousand Oaks, CA: Sage.

Stiglitz, J., Sen, A. and Fitoussi, J. (2009). Report by the Commission on the Measurement of Economic Performance and Social Progress. Brussels: EU.

Storey, R. and Storey, S. (1998) FASB special report, the framework of financial accounting concepts and standards. Norwalk, CT: FASB.

Suchman, 1995). Managing legitimacy: Strategic and institutional approaches. Academy of Management Review, 20, 571-610.

TFCD (2016). Recommendations of the Task Force on Climate-related Financial Disclosures.

Watts, R., (2003). Conservatism in accounting Part I: Explanations and implications, Accounting Horizons, 17, 207-221.

Waymire, G. B. 2009. Exchange guidance is the fundamental demand for accounting. The Accounting Review, 84 (1): 53-62.

Wilson, E.O. (2016). Half-Earth: Our Planet's Fight for Life. New York, NY: Liveright Publishing Corporation. 
Figure 1. Growth in Corporate Sustainability Reporting.

The chart shows the number of MNEs issuing a sustainability report, globally, based upon data in the Global Reporting Initiative (GRI) reporting database:

http://database.globalreporting.org/search/

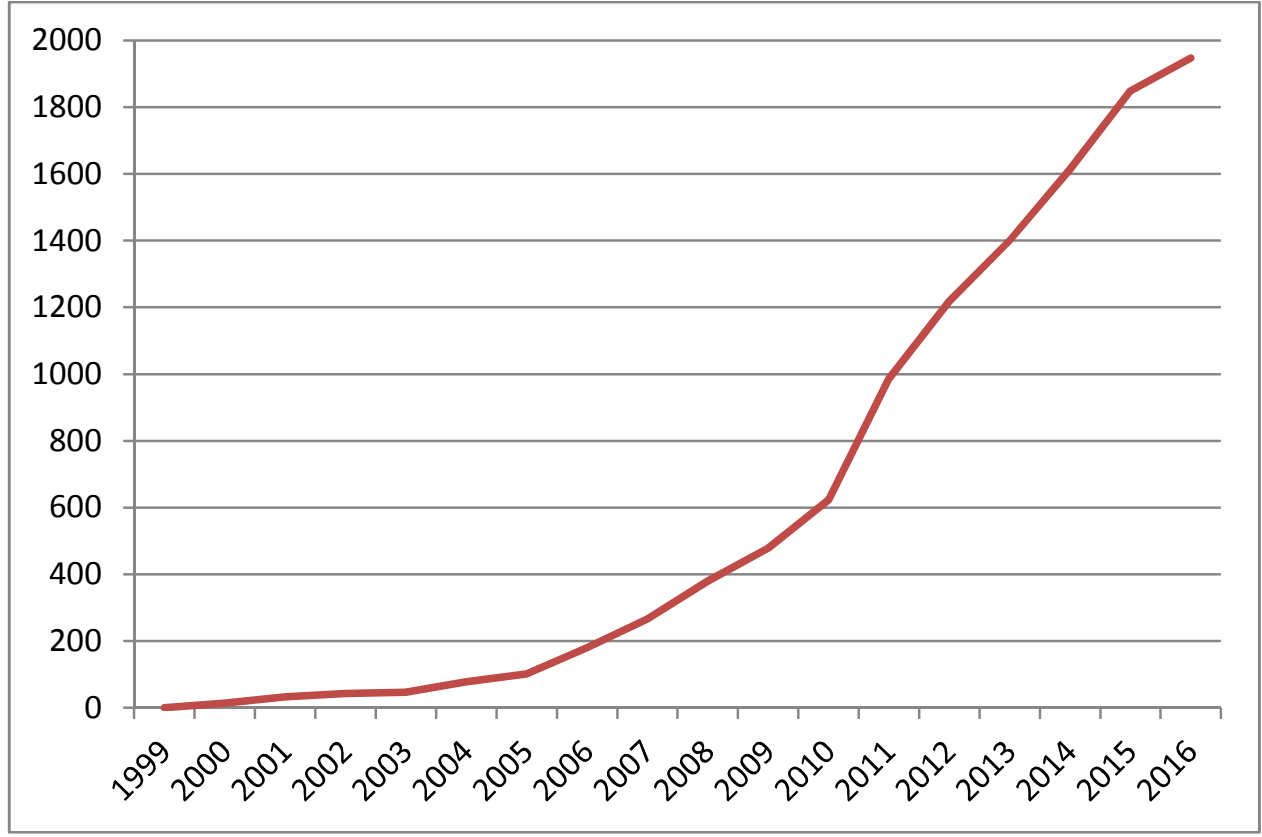


Table 2: Natural Capital balance sheet for RSPB nature reserves in England (RSPB, 2018)

2016/17 (PV £m)

Private value External value

Total value

\section{Assets}

\begin{tabular}{|lccc|}
\hline Baseline value (00/01) & $(73)$ & 681 & 608 \\
\hline Cumulative gains/losses & - & 170 & 170 \\
\hline Additions/disposals & 21 & 26 & 47 \\
\hline Revaluations and adjustments & 93 & 155 & 248 \\
\hline Gross asset value & 41 & 1,031 & 1,072 \\
\hline & - & & \\
\hline Liabilities & $(448)$ & $(80)$ & $(528)$ \\
\hline Legal maintenance obligations & $(448)$ & $(80)$ & $(528)$ \\
\hline Other maintenance provisions & & 951 & 544 \\
\hline Total net maintenance provisions & $(407)$ & & \\
\hline
\end{tabular}

Table 2. Accounting and Reporting Standards and Frameworks

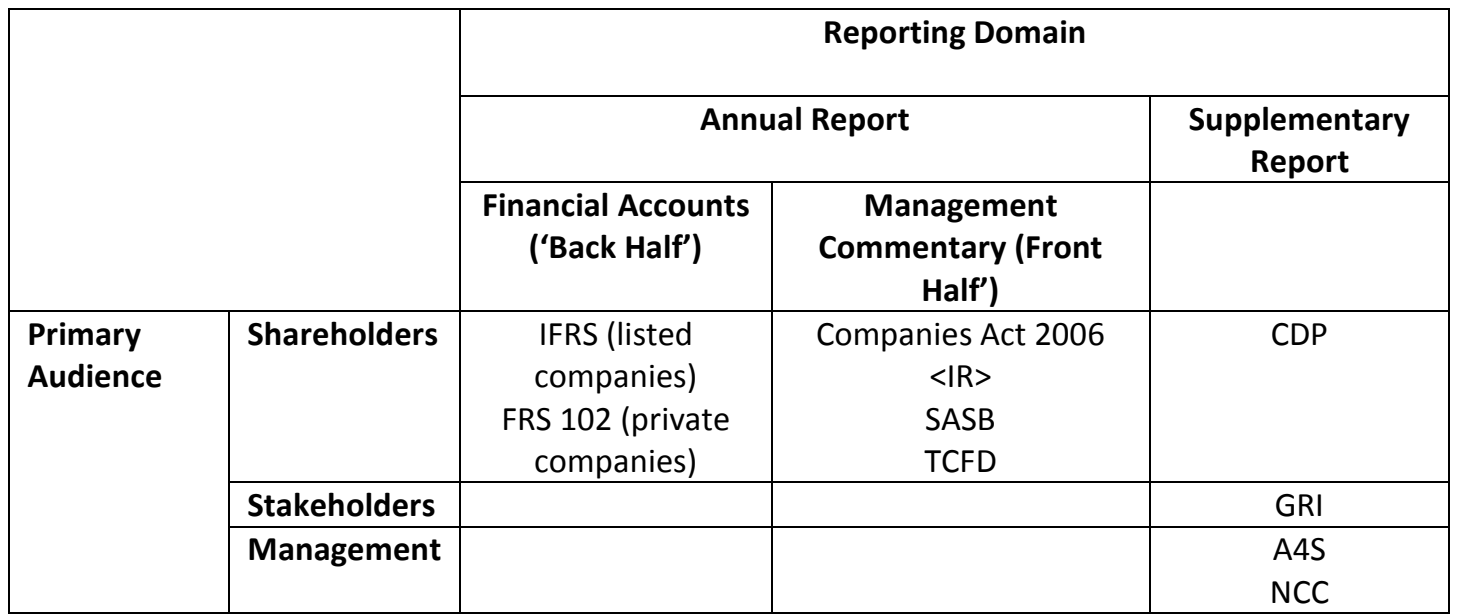

